Article

\title{
Assessing the Performance of Different Grains in Gluten-Free Bread Applications
}

\author{
Iuliana Banu and Iuliana Aprodu * \\ Faculty of Food Science and Engineering, Dunarea de Jos University of Galati, 111 Domneasca Str., \\ 800201 Galati, Romania; iuliana.banu@ugal.ro \\ * Correspondence: iuliana.aprodu@ugal.ro
}

Received: 19 November 2020; Accepted: 7 December 2020; Published: 8 December 2020

check for updates

\begin{abstract}
A comparative analysis of quinoa, sorghum, millet and rice flours and breads in terms of proximate composition, resistant starch, antioxidant activity and total phenolic content was realized in this study. Quinoa whole flour had the highest content of proteins, fat, ash and total dietary fiber, followed by millet and sorghum flours. Quinoa and rice breads had higher specific volume (192.22 and $181.04 \mathrm{~cm}^{3} / 100 \mathrm{~g}$, respectively) and lower crumb firmness (10.81 and 13.74 N, respectively) compared to sorghum and millet breads. The highest total phenol content was obtained in the case of bread prepared with quinoa flour (398.42 mg ferulic acid equiv/100 g d.w.), while the lowest content was obtained for the rice flour bread (70.34 $\mathrm{mg}$ ferulic acid equiv/100 $\mathrm{g} \mathrm{d} . \mathrm{w})$. The antioxidant activity of gluten-free breads decreased in the following order: sorghum $>$ quinoa $>$ millet $>$ rice. Quinoa bread had the highest resistant starch content of $3.28 \%$ d.w., while the rice bread had the highest digestible starch content of $81.48 \%$ d.w. The slowly digestible starch varied from $15.5 \%$ d.w. for quinoa bread, to $6.51 \%$ d.w. for millet bread. These results revealed the huge potential of quinoa, sorghum and millet to be used for developing functional gluten-free bread.
\end{abstract}

Keywords: quinoa; millet; sorghum; rice; gluten-free bread

\section{Introduction}

Coeliac disease is a lifelong autoimmune enteropathy induced by gluten consumption, affecting persons which are genetically susceptible. Due to the increasing prevalence worldwide, the coeliac disease started to be considered a major public health problem [1]. Taking into account that no efficient cure was reported yet for this condition, avoidance of gluten-containing products in the diet was recommend as the main solution. Therefore, identifying ingredients and tools for obtaining high-quality gluten-free products is highly desired. Rice flour is considered the most important ingredient in gluten-free bread making, but in the last period the minor grains like millet, sorghum and quinoa became increasingly important for producing gluten-free baking products [2].

Originating from South America but with a great adaptability to different growing conditions, quinoa has become more and more popular due to the well-balanced nutritional composition [3-5]. Quinoa is recommended primarily by the content and quality of its proteins, being rich in amino acids which are deficient in cereals. In fact, the amino acids composition of quinoa proteins is close to the ideal protein recommended by FAO [3,6-8]. In addition, quinoa contains high levels of unsaturated fatty acids [9-11], vitamins [9], minerals [12], dietary fiber and polyphenols [13].

Sorghum and millet are two cereals which are insufficiently used in bakery products, even if they have nutritional compositions comparable to other cereals [14], and could be used if not as the based flour, at least as functional ingredients, mainly due to phenolic compounds $[2,15,16]$ and resistant starch contents $[14,17]$. Moreover, the two cereals can be grown on semi-arid regions, where other cereals do not give consistent productions. 
Several studies pointed out that quinoa, sorghum and millet have huge potential to be used for developing functional foods, due to the high level of phenolic compounds, antioxidant capacity and low starch digestibility $[2,3,17]$.

The objective of this study was to compare quinoa, sorghum, millet and rice in terms of composition, bread-making potential and physical properties, resistant starch, antioxidant activity and total phenolic content of breads. The rice was included in this study due the large applications in gluten-free bread making.

\section{Materials and Methods}

\subsection{Materials}

The quinoa seeds (Titicaca variety cultivated through conventional farming in Galati, Romania, harvest, 2017) used in the experiments were preliminary treated to eliminate the bitter taste and toxic saponins using the procedure described by Nascimento et al. [18]. Quinoa was washed with tap water for $20 \mathrm{~min}$, then the seeds were dried at $45^{\circ} \mathrm{C}$ for $12 \mathrm{~h}$. After drying the seeds were ground using a blade mill grinder (Bosch MKM6003, Gerlingen, Germany). The quinoa whole flour was then stored at $4{ }^{\circ} \mathrm{C}$ until further analyses.

The sorghum whole flour (origin Hungary, distributed by Adams Vision SRL Tg Mures, Romania), brown millet flour (distributed by La Finestra sul Cielo Vilareggia Italia) and wholegrain rice flour (Solaris Plant SRL, Bucharest, Romania) were purchased from the local market (Galati, Romania).

Other ingredients used for bread making, such as salt, sugar, lecithin and compressed yeast, were purchased from local market (Galati, Romania).

\subsection{Proximate Compositions}

The proximate composition of quinoa, sorghum, millet and rice whole flours was determined as follows: moisture content with SR ISO 712:2005 [19], protein content through semimicro-Kjeldahl method (Raypa Trade, R Espinar, SL, Barcelona, Spain) using a nitrogen-to-protein conversion factor of 6.25 (AACC method 46-11.02 [20]), fat content through Soxhlet extraction method (SER-148; VELP Scientifica, Usmate Velate (MB), Italy) with ether, total, insoluble and soluble dietary fiber contents with a combination of enzymatic and gravimetric methods [21] (Merck KGaA, Darmstadt, Germany) and ash contents with SR ISO 2171/2002 [19]. The starch contents were afterwards determined by subtracting from one hundred the total percentage of the components experimentally assayed.

Amylose content was determined using the Amylose/Amylopectin Assay Kit and the procedure recommended by the manufacturer (Megazyne International Ireland Ltd. Wicklow, Ireland), which is based on the method of Gibson et al. [22].

The starch damage was determined though AACC Method 76-31.01 [20], using the dedicated kit from Megazyme International Ireland Ltd. (Wicklow, Ireland).

\subsection{Physical Properties}

Fineness module was determined using the method of Godon and Willm [23], the flour being sieved through 500, 400, 315, 160 and $125 \mu \mathrm{m}$ mesh.

The brightness value $\left(\mathrm{L}^{*}\right)$, redness value $\left(\mathrm{a}^{*}\right)$ and yellowness value $\left(\mathrm{b}^{*}\right)$ were measured using the Chroma Meter CR-410 (Konica Minolta Business Solutions Europe GmbH). Furthermore, based on a* and $b^{*}$ values, the chroma $\left(C^{*}\right)$ and hue angle $\left(h^{\circ}\right)$ were calculated.

\subsection{Bread-Making Procedure}

The doughs were prepared through the one stage method described by Banu et al. [24], using the following formula on a $100 \mathrm{~g}$ whole flour: $1.5 \%$ salt, $2 \%$ sugar, $6 \%$ lecithin, $3 \%$ compressed baker's yeast, and water $(78 \mathrm{~mL})$. The dough was fermented for $150 \mathrm{~min}$ at $30{ }^{\circ} \mathrm{C}$ in a laboratory proofer, 
was divided in two pieces, molded and placed in baking trays. After the additional leavening of $30 \mathrm{~min}$ at $30^{\circ} \mathrm{C}$, the samples were baked for $30 \mathrm{~min}$ at $230^{\circ} \mathrm{C}$

\subsection{Breads Characterization}

Prior to characterization, the breads were stored for $60 \mathrm{~min}$ at room temperature.

The specific volume of the bread samples was measured through the rapeseed displacement method [19].

Crumb firmness was determined using the MLFTA apparatus (Guss, Strand, South Africa) and a probe with diameter of $7.9 \mathrm{~mm}$. Three distinct measurements were performed on two bread slices originating from the center of the bread samples. The following parameters were considered when measuring the crumb firmness: test speed of $5 \mathrm{~mm} / \mathrm{s}$, trigger threshold force of $1.96 \mathrm{~N}$ and bread slices penetration wide of $25 \mathrm{~mm}$.

In order to determine the total phenolic content, 2,2-diphenyl-1-picrylhydrazyl (DPPH) radical scavenging activity, trolox equivalent antioxidant capacity and iron reducing antioxidant power, the extraction procedure described by Aprodu and Banu [25] was used.

The total phenolic content, the DPPH-radical scavenging activity, the Trolox equivalent antioxidant capacity (TEAC) and the ferric reducing antioxidant power (FRAP) were determined using the procedures described by Aprodu and Banu [25]. The total phenolic content was reported as mg ferulic acid equivalent (FAE) per $100 \mathrm{~g}$ d.w. bread sample, the TEAC was expressed as $\mu$ mols Trolox/g d.w., while results of the FRAP were expressed in $\mu \mathrm{mol} \mathrm{Fe} e^{2+} / \mathrm{g}$ d.w.

The content of resistant starch was determined through the AACC Method 32-40.01 [20], using the Megazyne assay kit (Megazyne International Ireland Ltd. Wicklow, Ireland).

Rapidly and slowly digestible starch contents were determined using the procedure described by Miao et al. [26]. The glucose content of the samples was determined using the glucose oxidase/peroxidase (GOPOD) assay kits (Wicklow, Ireland). The amount of hydrolyzed starch was determined by multiplying the assayed glucose content by a factor of 0.9. Finally, the rapidly and slowly digestible starch values were obtained by considering the contents of glucose released after $20 \mathrm{~min}$ and $120 \mathrm{~min}$ (G20 and G120, respectively) and free glucose (FG).

\subsection{Statistical Analysis}

The results are reported as average values of three replicates together with standard deviation. Analysis of variance was carried out with Microsoft Excel Soft to detect significant differences among results. Pearson's correlation coefficients were calculated to identify eventual statistical relationships.

\section{Results and Discussion}

\subsection{Proximate Composition of Flours}

The proximate composition of quinoa, millet, sorghum and rice whole flours is shown in Table 1. The highest proteins content of $14.05 \%$ was registered for quinoa flour. According to Basile et al. [4], quinoa has a similar protein content with the highest strains of wheat, with lower amounts of glutinous proteins. In addition, quinoa was reported as a source of complete protein, having a well-balanced amino acids composition needed for human diet, having high contents of methionine and lysine [6]. Moreover, Vega-Galvez et al. [6] noted that the value of quinoa protein is similar to casein in milk. According to Srichuwong et al. [8] the percentage of lysine in the quinoa proteins is $6.9 \%$, much higher than in sorghum $(2.2 \%)$, millet $(3.1 \%)$ or wheat $(2.9 \%)$. Regarding the methionine content of the total proteins from quinoa, millet and sorghum, the percentages are in the $2.5-3.6 \%$ range, significantly higher compared to wheat proteins which have 1.8\% [8]. Fairbanks et al. [27] appreciated that the high level of lysine from quinoa proteins is due to the high amount of albumins and globulins which are rich in this amino acid. 
Table 1. Proximate compositions of whole quinoa, sorghum, millet and rice flours (\% d.w.).

\begin{tabular}{ccccc}
\hline Component & Quinoa Flour & Sorghum Flour & Millet Flour & Rice Flour \\
\hline Protein, \% & $14.05 \pm 0.07$ & $10.29 \pm 0.03$ & $11.01 \pm 0.06$ & $6.18 \pm 0.03$ \\
Fat, \% & $5.29 \pm 0.06$ & $3.17 \pm 0.03$ & $3.91 \pm 0.05$ & $2.16 \pm 0.03$ \\
Ash, \% & $2.39 \pm 0.01$ & $1.61 \pm 0.01$ & $2.70 \pm 0.01$ & $1.53 \pm 0.01$ \\
Total dietary fiber, \% & $9.11 \pm 0.08$ & $7.42 \pm 0.06$ & $8.57 \pm 0.08$ & $4.69 \pm 0.06$ \\
Insoluble dietary fiber, \% & $6.74 \pm 0.05$ & $6.52 \pm 0.04$ & $7.46 \pm 0.05$ & $3.72 \pm 0.03$ \\
Soluble dietary fiber, \% & $2.36 \pm 0.02$ & $0.90 \pm 0.01$ & $1.10 \pm 0.01$ & $0.97 \pm 0.01$ \\
Starch, \% & $58.84 \pm 0.07$ & $69.63 \pm 0.06$ & $63.92 \pm 0.07$ & $74.09 \pm 0.05$ \\
Amylose, \% starch & $17.76 \pm 0.08$ & $23.23 \pm 0.10$ & $20.36 \pm 0.11$ & $19.92 \pm 0.09$ \\
\hline
\end{tabular}

The proteins content of sorghum whole flour was $10.29 \%$, close to the results reported by Khan et al. [14] for red sorghum whole flour (10.05\%) and white sorghum whole flour $(11.77 \%)$. Mokrane et al. [28] analyzed the sorghum protein quality, and observed the high amino acid scores that varied between 0.9 and 2.6, except for lysine, methionine and cysteine. The sorghum proteins include albumins, globulins, kafirins, cross-linked kafirins and glutelins, among which the kafirins represent about $80 \%$ of decorticated flour protein [29].

In case of millet, the proteins content was $11.01 \%$, comparable to the value of $10.75 \%$ reported by USDA [30]. According to Devi et al. [31], different millet species present large variations of proteins content, ranging from $7.3-8.3 \%$ in case of finger and kodo millet, to $14.5 \%$ in case of pearl millet; the proso and foxtail millet have protein contents of $11-11.3 \%$. Kalinova and Moudry [32] reported for proso millet proteins an essential amino acid index of 0.51 , and the amino acids scores of 0.47 for lysine, of 0.78 for tyrosine and of 0.75 of cysteine and methionine.

Among the investigated whole protein flours, the smallest proteins content of $6.18 \%$ was registered for rice flour (Table 1), lower compared to the results of $7.23 \%$ reported by USDA [30], or $7.5 \%$ by Devi et al. [31].

The results shown in Table 1 indicated that the fat content varied from $5.29 \%$, for quinoa flour, to $2.16 \%$, for rice flour. Higher fat contents of $6.0,6.4$ and $6.8 \%$ were reported by Pereira et al. [10] for whole quinoa white grain, red grain and black grain, respectively. On the other hand, Vidueiros et al. [11] reported lower fat content of $4.7-5.3 \%$ for different varieties of quinoa. Sorghum and millet flours presented fat contents of 3.17 and 3.91\%, respectively, while Srichuwong et al. [8] reported values of 5 and $3.7 \%$, in case of white and red sorghum, and $4.1 \%$ for millet flour. The fat content of rice whole flour was $2.16 \%$.

The lipids are divided into free and bound fractions, the free lipids being the most present fractions [6]. Ragaee et al. [16] reported the presence of free lipid fractions of 2.0-4.1 and 5.6\%, and of $0.1-0.56$ and $0.6-0.9 \%$ for bound fractions in sorghum and millet, respectively. In case of quinoa flour, Collar and Angioloni [6] reported for free and bound lipids fractions values of 3.23 and $0.28 \mathrm{~g} / 100 \mathrm{~g}$ flour, respectively.

The lipid composition of quinoa stands out in the relation to the rest of cereals analyzed, through the fatty acid profile that is comparable to that of corn and soybeans [9]. The major saturated fatty acid is palmitic acid (about 10\%), while the oleic, linoleic and alpha-linolenic acids represents about 19.7-29.5, 49-56.4 and 8.7-11.7\%, respectively [8-10]. According to Rooney [33], when compared to quinoa, the sorghum and millet grains contain higher levels of palmitic acid (of 12 and 20\%, respectively), oleic acid (34 and 26\%, respectively), and lower levels of linoleic acid (of 50 and $45 \%$, respectively), and linolenic acid (of 3 and $4 \%$, respectively).

The ash content of millet (2.7\%) and quinoa (2.39\%) flours is higher compared to rice and sorghum flours that had values of 1.53 and $1.61 \%$, respectively (Table 1). The ash content of quinoa flour used in the present study is lower than that reported by other authors [11], probably due the intensity of the washing process of grains. On the other hand, in case of rice flour the ash content was higher than that reported by other authors [34]. Instead, in case of sorghum and millet our results were between the values reported by other authors, namely $2-3.6 \%$ [31] and $1.52-2.57 \%$ [14], respectively. 
The highest amounts of total dietary fibers were registered in case of quinoa and millet flours, of 9.11 and $8.57 \%$, respectively, whereas the rice flour had the lowest total dietary fiber content $(4.69 \%)$ among the investigated grains. The soluble fiber content ranged between 2.36 , in quinoa flour, and $0.90 \%$ in sorghum flour. The insoluble fiber content decreased in the following order: millet $(7.46 \%)$, quinoa $(6.74 \%)$, sorghum $(6.52 \%)$ and rice $(3.72 \%)$ flours. The results reported by different authors present a large variation, even if the same method used for investigations. For instance, Srichuwong et al. [8] reported much lower value for total fiber content for quinoa and millet $(9.5 \%$ and 8.4-10\%, respectively), compared to the Kurek et al. [35] (16.43\% and $11.71 \%$, respectively), even if the authors used the same method. These results highlight the great variability in terms of chemical composition among grain varieties.

Regarding fiber compositions, Lamothe et al. [36] reported that, in case of quinoa, the soluble and insoluble dietary fiber were composed mainly of pectic polysaccharides and xyloglucans, unlike cereals that contain mostly arabinoxylans. Lai et al. [37] reported that the total dietary fiber extracted from nonwaxy brown rice contained important amount of pectic substances, whereas the waxy counterparts were richer in hemicellulose or cellulose.

Due to the high contents of protein, fiber, fat and ash from quinoa, sorghum and millet flours, the amount of starch present in the samples was lower compared to the rice flour (Table 1). The lowest starch content was registered in case of quinoa flour ( $58.84 \%)$, followed by millet and sorghum flours, while the highest value was obtained for rice flour $(74.09 \%)$. The amylose content in starch varied from 17.76 for quinoa to $23.23 \%$ for sorghum flours. Navruz-Varli and Sanlier [9] showed that the amylose content in the quinoa starch can vary from 3 to $22 \%$, being lower than in wheat. The amylose content of rice starch depends by type of rice. Thus, Chung et al. [38] reported value of $27.2 \%$ of the amylose content for the rice starch isolated from long grains, and significantly lower values of 15.4 and $18.8 \%$ for the amylose contents for the rice starches isolated from medium and round grains, respectively. Srichuwong et al. [8] reported for millet and sorghum starches values of amylose about of 24 and $24.6-25.8 \%$, respectively.

\subsection{Physical Properties of Flours}

The granularity of the flour samples is an important physical parameter because of the high influence on the quality of the bakery products. The granularity of the flours was estimated by determining the tailing and sieve fractions on a set of sieves with mesh aperture ranging from 500 to $125 \mu \mathrm{m}$, and the fineness modulus.

The sorghum and millet flours had highest percentage of particles with size between 125 and $315 \mu \mathrm{m}$, of 80.7 and $74.9 \%$, respectively (Table 2). In case of rice flour highest percentage of particles had larger size, ranging between 315 and $500 \mu \mathrm{m}$, while in case of quinoa flour the particles size was most homogenous, even if the percentage of particles with size between 125 and $315 \mu \mathrm{m}$ was about two times higher than of those between 315 and $500 \mu \mathrm{m}$, and three times higher than of those with size less than $125 \mu \mathrm{m}$. The higher percentage of larger particles in case of rice flour resulted in higher fineness module (of 2.85) compared to the rest of flours. Sorghum flour had the lowest percentage of particles higher than $315 \mu \mathrm{m}$ and the lowest fineness module of 1.63.

The fineness module is a measure of the distribution of fine and coarse particles in the analyzed sample, and can be influenced on one hand by grains related factors such as compactness of the endosperm, composition and texture of the pericarp and embryo, and by the milling method on the other hand. Taking into account that sorghum, millet and rice flours are commercial flours, it was not possible to factor the effect of grinding on the particle size distribution. Anyway, the difference between the values of the fineness modulus of the investigated flour might be due to the differences in terms of compactness of the rice endosperm. 
Table 2. Physical properties of whole quinoa, sorghum, millet and rice flours.

\begin{tabular}{|c|c|c|c|c|c|}
\hline \multicolumn{2}{|c|}{ Properties } & Quinoa Flour & Sorghum Flour & Millet Flour & Rice Flour \\
\hline \multicolumn{2}{|c|}{ Fineness module } & $2.31 \pm 0.03$ & $1.63 \pm 0.02$ & $1.90 \pm 0.02$ & $2.85 \pm 0.03$ \\
\hline \multicolumn{2}{|c|}{ - Particles size 500-315 $\mu \mathrm{m}, \%$} & $35.9 \pm 0.11$ & $10.0 \pm 0.10$ & $18.7 \pm 0.10$ & $59.5 \pm 0.11$ \\
\hline \multicolumn{2}{|c|}{ - Particles size $315-125 \mu \mathrm{m}, \%$} & $46.0 \pm 0.10$ & $80.7 \pm 0.12$ & $74.9 \pm 0.12$ & $32.7 \pm 0.10$ \\
\hline \multicolumn{2}{|c|}{ - Particles size $<125 \mu \mathrm{m}, \%$} & $18.1 \pm 0.09$ & $9.3 \pm 0.08$ & $7.0 \pm 0.07$ & $7.8 \pm 0.05$ \\
\hline \multicolumn{2}{|c|}{ Damaged starch, \% } & $4.44 \pm 0.05$ & $8.17 \pm 0.06$ & $5.27 \pm 0.05$ & $3.85 \pm 0.05$ \\
\hline \multirow{5}{*}{ Color values } & $\mathrm{L}^{*}$ & $81.46 \pm 0.16$ & $81.62 \pm 0.16$ & $83.79 \pm 0.29$ & $83.89 \pm 0.62$ \\
\hline & $a^{*}$ & $1.32 \pm 0.05$ & $4.49 \pm 0.02$ & $2.62 \pm 0.01$ & $0.59 \pm 0.01$ \\
\hline & $b^{*}$ & $15.28 \pm 0.12$ & $12.45 \pm 0.39$ & $15.18 \pm 1.12$ & $15.33 \pm 0.06$ \\
\hline & $C^{*}$ & $15.34 \pm 0.43$ & $13.23 \pm 0.01$ & $15.40 \pm 0.02$ & $15.34 \pm 0.02$ \\
\hline & $h^{\circ}$ & $56 \pm 0.00$ & $51 \pm 0.00$ & $54 \pm 0.01$ & $57 \pm 0.00$ \\
\hline
\end{tabular}

The starch damaged of sorghum flour (8.17\%) was higher than other flours (3.85-4.44\%) (Table 2). A positive correlation of 0.87 was registered between the fineness module and damaged starch $(p<0.05)$.

The color parameters of the investigated flours are presented in Table 2. The lowest lightness values $\left(L^{*}\right)$ were obtained in case of quinoa and sorghum flours. Sorghum flour presented the highest value of redness $\left(a^{*}\right)$ and lowest values of yellowness $\left(b^{*}\right)$, chroma $\left(C^{*}\right)$ and hue angle $\left(h^{\circ}\right)$, and most probably these values might be explained by the presence of colored polyphenolics such as tannins and anthocyanins [17]. On the other hand, the higher values of yellowness $\left(b^{*}\right)$ registered in case of quinoa, millet and rice flour might be explained by the presence of carotenoids in these samples [39].

\subsection{Breads Characterization}

Sorghum and millet breads are characterized by lower specific volumes and higher crumb firmness compared to quinoa and rice flour breads (Table 3). Marston et al. [40] reported an improvement of the specific volume and crumb firmness of gluten-free breads based on heat-treated sorghum flour compared to the unheated flour. The authors noted that these results are possible due the modification of sorghum proteins by oxidizing the free sulfhydryl groups. Moreover, Taylor et al. [2] suggested that the lack of glyco- and phospholipids in sorghum flour might be a reason for the lower volume of the bread prepared with sorghum flour compared to the wheat. In addition to starch, the properties of the lipids influence to high extent the crumb firmness.

Table 3. Physical properties of quinoa, sorghum, millet and rice breads.

\begin{tabular}{ccccc}
\hline \multirow{2}{*}{ Physical Properties } & \multicolumn{4}{c}{ Breads Prepared With } \\
\cline { 2 - 5 } & Quinoa Flour & Sorghum Flour & Millet Flour & Rice Flour \\
\hline Specific volume, $\mathrm{cm}^{3} / 100 \mathrm{~g}$ & $192.22 \pm 0.12$ & $152.35 \pm 0.10$ & $164.39 \pm 0.11$ & $181.04 \pm 0.12$ \\
Crumb firmness, N & $10.81 \pm 0.14$ & $21.47 \pm 0.32$ & $25.70 \pm 0.15$ & $13.74 \pm 0.23$ \\
\hline
\end{tabular}

The quinoa bread had the highest specific volume and lowest crumb firmness. Elgeti et al. [1] reported enhanced specific volume of the bread made with quinoa flour compared to the bread made with a blend of rice and corn flours. The authors explained these results through the better ability of the dough prepared with quinoa flour to retain a high amount of gas. It is well known that the proteins from rice flour do not have great gas retention properties [41]. The high gas volume resulting throughout fermentation was stabilized within the network during baking, resulting in a nice structure with homogeneously distributed fine pores. It was considered that different surface-active components present in quinoa flour, such as peptides or polar lipids, might contributed to the stabilization of the gas bubbles. In addition, the viscoelastic properties of the dough might be optimized such as to allow easier and more efficient gas inclusion and stabilization. Furthermore, Elgeti et al. [1] noted that specific volume of bread increased when quinoa flour was used to replace the quinoa whole 
flour. They considered that the positive effect registered on the volume of the bread was the result of removing the embryo hull components out of the whole flour. As previously shown, the bran particles might interfere with gas cells, affecting the porosity and specific volume bread [42].

\subsection{Antioxidant Activity of the Breads}

The total phenol contents and antioxidant activity of quinoa, sorghum, millet and rice breads are reported in Table 4. The total phenol content of the breads varied from 70.34 to $398.42 \mathrm{mg} \mathrm{FAE} / 100 \mathrm{~g}$ d.w. The highest total phenol content was registered in case of bread prepared with quinoa flour, while the lowest content was obtained for bread prepared with rice flour.

Table 4. Total phenol contents and antioxidant activity of quinoa, sorghum, millet and rice breads.

\begin{tabular}{ccccc}
\hline \multirow{2}{*}{ Properties } & \multicolumn{4}{c}{ Breads Prepared With } \\
\cline { 2 - 5 } & Quinoa Flour & Sorghum Flour & Millet Flour & Rice Flour \\
\hline $\begin{array}{c}\text { Total phenol content, mg ferulic acid } \\
\text { equiv/100 g d.w. }\end{array}$ & $398.42 \pm 0.15$ & $387.16 \pm 0.11$ & $180.09 \pm 0.10$ & $70.34 \pm 0.10$ \\
\hline DPPH-radical scavenging activity, $\%$ & $32.85 \pm 0.11$ & $35.01 \pm 0.10$ & $19.24 \pm 0.10$ & $10.50 \pm 0.11$ \\
\hline FRAP, $\mu$ moli Fe ${ }^{2+} / g$ d.w. & $2.53 \pm 0.09$ & $3.67 \pm 0.09$ & $2.06 \pm 0.07$ & $0.98 \pm 0.05$ \\
\hline TEAC, $\mu$ moli Trolox/g d.w. & $19.32 \pm 0.12$ & $54.51 \pm 0.12$ & $15.07 \pm 0.10$ & $6.97 \pm 0.10$ \\
\hline
\end{tabular}

The antioxidant properties of breads were evaluated by measuring the DPPH-radical scavenging activity, and by TEAC and ABTS and FRAP methods. Re et al. [43] mentioned that the TEAC method quantifies both lipophilic and hydrophilic antioxidants, comprising carotenoids, hydroxycinnamates, and flavonoids, while the DPPH-radical scavenging activity is mainly due to the phenolic compounds [25]. In order to directly measure the antioxidants or reductants in samples the FRAP assay was used.

All methods applied for assessing the antioxidant properties indicated that the antioxidant ability of the bread samples decreased in the following order: sorghum $>$ quinoa $>$ millet $>$ rice (Table 4 ). Sorghum and quinoa breads had higher value of FRAP, indicating the presence of $\mathrm{Fe}^{2+}$ chelating agents in these samples.

The results reported in the literature for the antioxidant activity of different types of flours and breads are very different due to many factors related both to the investigated samples, such as the genotype of the grains and environmental conditions, and to the techniques used for preparing the extracts and quantification of the antioxidant activity [13]. Therefore, is rather difficult to compare our results with those of other authors. Xu et al. [3] studied the antioxidant properties of bread prepared with blends of wheat flour and quinoa flour and found that the phenolic content, ABTS and DPPH-RSA increased with increase of the levels of quinoa flours. They reported a loss of total polyphenol after baking. Similarly, when testing the possibility of using amaranth, quinoa, buckwheat and wheat for obtaining nutritionally enhanced gluten-free formulations, Alvarez-Jubete et al. [44] reported the overall decrease of the antioxidant activity and total phenol content following bread making. Anyway, new substance with antioxidant properties can be synthesized during baking, such as Maillard reaction products, which can be mainly found in the bread crust. Jan et al. [45] observed the increase of the antioxidant activity of cookies during baking process with increasing the sugar level, temperature and time, most probably due to the formation of melanoidins. The antioxidant activity of cookies was stable after baking at $180^{\circ} \mathrm{C}$ suggesting the completion of the reactions resulting in molecules with radical scavenging ability. Furthermore, the phenolics breakdown or other degradation reactions might result in products responsible for the increase antioxidant activity. Lindenmeier and Hofmann [46] reported the increase of the antioxidant activity up to five times with the increase of baking temperature and time. They explained this increase by the formation of the antioxidant compound pronyl-L-lysine. Moreover, they found higher antioxidant activity in crust in comparison to the crumb and untreated flour. 
Khan et al. [14] reported for the free phenolic acids of red and white sorghum flours values of 81.19 and $150.67 \mu \mathrm{g} \mathrm{GAE} / \mathrm{g}$ d.w., respectively. Yousif et al. [17] found that the breads prepared from blends of wheat flour and $40 \%$ sorghum flour (red and white, respectively) had the free phenolic contents of 1.09-0.49 mg GAE/g d.w. Additionally, Yousif et al. [17] reported that the addition of red or white sorghum flour to the wheat flour increased the polyphenolic content and the antioxidant capacity of the bread. Khan et al. [14] noted that the phenolic acids prevailing in the extract were ferulic acid, p-hydroxibenzoic acid and salicylic acid. Besides these phenolic acids, the red sorghum flour contained flavonoids such as anthocyanins (luteolinidin and apigeninidin). Thermal processing of cereals usually causes the reduction of the flavonoid contents to different extents, depending on the food matrix and on the intensity of the thermal treatment [44]. In particular, Khan et al. [14] noted that anthocyanins were less stable than phenolic acids during cooking. There are other phytochemicals, such as carotenoids, that contribute to the antioxidant activity of the samples [14]. Lopez-Contreras et al. [47] studied the antioxidant activity of ten sorghum genotypes and reported variation of the FRAP, ABTS and DPPH values from 3.94 to 63.34 , from 44.21 to 121.73 and from 1.83 to $65.73 \mu \mathrm{mol}$ Trolox/g, respectively, and of total phenol content values from 1.408 to $12.348 \mu \mathrm{g}$ catechin equivalents/g.

Chandrasekara and Shahidi [15] found higher free phenolic contents in finger millet (411-610 mg FAE/100 g), compared to the pearl and proso millets (168 mg FAE/100 $\mathrm{g}$ and $140 \mathrm{mg}$ FAE/100 $\mathrm{g}$, respectively). They registered different flavonoid contents of 203-228, 49 and $140 \mathrm{mg} / 100 \mathrm{~g}$ catechin equivalent in the phenolic extracts obtained from finger, pearl and proso millet, respectively. Chethan and Malleshi [48] showed that the main phenolic acids in millets are ferulic acid, gallic acid, p-hydroxibenzoic acid, cumaric acid and proto-catechuic acid. Sreeramulu et al. [49] found higher antioxidant activity (FRAP of $471.71 \mu \mathrm{mol} / \mathrm{g}$, DPPH-RSA and total phenol content of 1.73 and $373.15 \mathrm{mg}$ Trolox $/ g$, respectively) in finger millet compared to the rice (FRAP of 60.93-67.48 $\mu \mathrm{mol} / \mathrm{g}$, DPPH-RSA and total phenol content of 0.49-1.23 and 47.64-56.61 mg Trolox/g, respectively).

Previous studies mentioned a significant correlation between phenolics and antioxidant activity in quinoa [50]. Large variation of the total phenol content of quinoa seed from 28.49 to $1.59 \mathrm{mg}$ gallic acid/100 g d.w. was reported by Miranda et al. [12]. Later study of Pellegrini et al. [13] revealed the phenolic profile of quinoa flour; the most abundant phenolic acids were 4-hydroxybenzoic, syringic acid, vanillic acid, gallic acid, ferulic acid and p-cumaric acid, while the most dominant flavonoids were neohesperidin, kaempfenol and isoquercitin. In addition to the polyphenols and flavonoids which are know the possess antioxidant properties, Aloisi et al. [50] also mentioned the contribution of the proteins, including the $11 \mathrm{~S}$ fraction, to the antioxidant activity of the quinoa seeds. Other bioactive compounds like carotene, vitamins, tocopherols etc., might also contribute to the antioxidant properties of quinoa flour [50].

The total phenol content and antioxidant properties varied significantly between breads prepared with quinoa, sorghum, millet and rice flour. Moreover, between the total phenol content and DPPH, FRAP and TEAC were registered strong correlations $(p<0.05)$ of $0.99,0.88$ and 0.71 , respectively. These results indicate that the antioxidant properties of breads are mainly due to presence of phenols and flavonoids.

\subsection{Starch Properties of Breads}

The contents of resistant and digestible starches are shown in Table 5. The quinoa bread had the highest amount of resistant starch of $3.28 \%$ d.w., while the rice bread had the highest amount of digestible starch of $81.48 \%$ d.w.

De la Hera et al. [51] prepared and characterized the gluten-free bread based on rice flour and reported resistant starch of $0.89-1.96 \mathrm{~g} / 100 \mathrm{~g}$ and rapidly digestible starch of 82.07-96.54 g/100 $\mathrm{g}$. They mentioned that the lowest values were obtained when coarse flour was used for samples preparation and dough had low hydration. 
Table 5. Rapidly and slowly digestible starch of quinoa, sorghum, millet and rice breads.

\begin{tabular}{ccccc}
\hline \multirow{2}{*}{ Properties } & \multicolumn{3}{c}{ Breads Prepared With } \\
\cline { 2 - 5 } & Quinoa Flour & Sorghum Flour & Millet Flour & Rice Flour \\
\hline Resistant starch, \% d.w. & $3.28 \pm 0.07$ & $2.79 \pm 0.06$ & $1.83 \pm 0.05$ & $1.40 \pm 0.05$ \\
Rapidly digestible starch, g/100 g starch d.w. & $48.31 \pm 0.10$ & $60.53 \pm 0.10$ & $63.26 \pm 0.11$ & $73.23 \pm 0.11$ \\
Slowly digestible starch, g/100 g starch d.w. & $15.50 \pm 0.11$ & $11.86 \pm 0.10$ & $6.51 \pm 0.10$ & $8.25 \pm 0.10$ \\
Digestible starch, g/100 g starch d.w. & $63.81 \pm 0.11$ & $72.39 \pm 0.11$ & $69.77 \pm 0.11$ & $81.48 \pm 0.11$ \\
\hline
\end{tabular}

When analyzing the red and white sorghum flour, Khan et al. [14] reported resistant starch contents of 2.95 and $2.21 \%$ d.w., respectively, higher than in durum wheat semolina $(0.42 \%$ d.w. $)$. The higher content of resistant starch of the sorghum flours could be the result of the inhibitory effect exerted on the digestive enzyme by the polyphenols or could be due to the interactions occurring between starch and proteins impeding the efficient enzyme recognition of the specific substrate [52]. The cooked pasta prepared with $40 \%$ red sorghum flour and with $40 \%$ white sorghum flour had 1.44 and $1.16 \%$ d.w. resistant starch, respectively.

Yousif et al. [17] found that wheat flour supplementation with red and white sorghum flour resulted in the increase of the resistant starch content of the bread samples from $30.1 \mathrm{~g} / 100$ dry starch up to 38.9 and $36.4 \mathrm{~g} / 100$ dry starch, respectively. The same authors reported lower rapidly digestible starch contents in the wheat bread samples containing red and white sorghum flour (27.7 and $29.0 \mathrm{~g} / 100$ dry starch), than in wheat bread ( $38.4 \mathrm{~g} / 100$ dry starch). Additionally, Yousif et al. [17] noted no correlation between the damaged starch content and starch digestibility of the sorghum containing breads. The activity of the in vitro digestive enzymes might have been limited when incorporating the sorghum flour into the wheat breads, through impeding the efficient starch gelatinization or through inhibition exerted by sorghum polyphenolics [52], therefore reducing the rapidly digestible starch levels. In fact, Taylor and Emmambux [52] mentioned no particular chemical or structural characteristics of sorghum starch, which might result in slow digestibility. It appears that the reduced digestibility arises from the presence of sorghum polyphenols and from the interactions between sorghum starch and proteins which are highly cross-linked through di-sulphide bridges [53].

$\mathrm{Xu}$ et al. [3] demonstrated that the wheat flour substitution with quinoa flour results in bread samples containing higher contents of slowly digestible starch and resistant starch and reduced in vitro digestibility with lower estimated glycemic index. The increase of the percentage of quinoa flour from 0 to $15 \%$ in wheat flour increased the resistant starch content of bread from 21.83 to $31.94 \%$, and decreased the rapidly digestible starch from 54.41 to $39.23 \%$ [3]. The authors explained that the high amounts of dietary fibers and polyphenols found in quinoa flour might have contributed to the decreased starch digestibility in bread with quinoa flour. The polyphenols might inhibit the activity of the amylases, by impeding the contact between enzymes and starch. Quinoa seeds appeared to be rich in insoluble simple or highly polymerized phenols which can be associated with the carbohydrates [50]. In addition, as suggested by Li et al. [54], the enzyme assisted starch hydrolysis might be significantly affected by the presence of high proportion of short chains of amylopectin.

\section{Conclusions}

The composition and physical properties, resistant starch, antioxidant activity and total phenolic content of quinoa, sorghum and millet revealed the huge potential of these flours to be used for developing functional gluten-free bread. All these flours have higher contents of proteins, fat and fiber compared to the rice flour, usually used in the gluten-free products as main ingredient. Compared to the rice bread, the quinoa bread had higher specific volume and lower crumb firmness, while sorghum and millet bread had lower specific volume and higher crumb firmness. All breads had the total phenol contents and antioxidant properties higher compared to the rice bread. Quinoa bread had the best physical properties, and the highest total phenol content. Additionally, quinoa bread had the highest resistant starch content among all investigated bread samples. These results indicate that quinoa demonstrated the highest potential to be used for obtaining high-quality gluten-free breads. 
Author Contributions: Conceptualization, I.A. and I.B.; methodology, I.B.; validation, I.A.; formal analysis, I.B.; investigation, I.B. and I.A.; writing-original draft preparation, I.B.; writing-review and editing, I.A.; supervision, I.A. All authors have read and agreed to the published version of the manuscript.

Funding: This research received no external funding.

Acknowledgments: The authors thank to Vitănescu Maricel for supplying the quinoa seeds.

Conflicts of Interest: The authors declare no conflict of interest.

\section{References}

1. Elgeti, D.; Nordlohne, S.D.; Foste, M.; Besl, M.; Linden, M.H.; Heinz, V.; Jekle, M.; Becker, T. Volume and texture improvement of gluten-free bread using quinoa white flour. J. Cereal Sci. 2014, 59, 41-47. [CrossRef]

2. Taylor, J.R.N.; Schober, T.J.; Bean, S.R. Novel food and non-food uses for sorghum and millets. J. Cereal Sci. 2006, 44, 252-271. [CrossRef]

3. Xu, X.; Luo, Z.; Yang, Q.; Xiao, Z.; Lu, X. Effect of quinoa flour on baking performance, antioxidant properties and digestibility of wheat bread. Food Chem. 2019, 294, 87-95. [CrossRef]

4. Bazile, D.; Bertero, H.D.; Nieto, C. State of the Art Report on Quinoa around the World in 2013; FAO, CIRAD: Santiago, Chile, 2015; p. 603.

5. Ruiz, K.B.; Biondi, S.; Oses, R.; Acuña-Rodríguez, I.S.; Antognoni, F.; Martinez-Mosqueira, E.A.; Coulibaly, A.; Canahua-Murillo, A.; Pinto, M.; Zurita, A.; et al. Quinoa biodiversity and sustainability for food security under climate change. A review. Agron. Sustain. Dev. 2014, 34, 349-359. [CrossRef]

6. Collar, C.; Angioloni, A. Pseudocereals and teff in complex breadmaking matrices: Impact on lipid dynamics. J. Cereal Sci. 2014, 59, 145-154. [CrossRef]

7. Vega-Galvez, A.; Miranda, M.; Vergara, J.; Uribe, E.; Puente, L.; Martinez, E.A. Nutrition facts and functional potential of quinoa (Chenopodium quinoa willd), an ancient Andean grain: A review. J. Sci. Food Agric. 2010, 90, 2541-2547. [CrossRef] [PubMed]

8. Srichuwong, S.; Curti, D.; Austin, S.; King, R.; Lamothe, L.; Hernandez, H.G. Physicochemical properties and starch digestibility of whole grain sorghums, millet, quinoa and amaranth flours, as affected by starch and non-starch constituents. Food Chem. 2017, 233, 1-10. [CrossRef]

9. Navruz-Varli, S.; Sanlier, N. Nutritional and health benefits of quinoa (Chenopodium quinoa Willd). J. Cereal Sci. 2016, 69, 371-376. [CrossRef]

10. Pereira, E.; Encina-Zelada, C.; Barrosa, L.; Gonzales-Barrona, U.; Cadaveza, V.; Ferreira, I. Chemical and nutritional characterization of Chenopodium quinoa Willd (quinoa) grains: A good alternative to nutritious food. Food Chem. 2019, 280, 110-114. [CrossRef]

11. Vidueiros, S.M.; Curti, R.N.; Dyner, L.M.; Binaghi, M.J.; Peterson, G.; Bertero, H.D.; Pallaro, A.N. Diversity and interrelationships in nutritional traits in cultivated quinoa (Chenopodium quinoa Willd.) from Northwest Argentina. J. Cereal Sci. 2015, 62, 87-93. [CrossRef]

12. Miranda, M.; Vega-Galvez, A.; Lopez, J.; Parada, G.; Sanders, M.; Aranda, M.; Uribe, E.; Di Scala, K. Impact of air-drying temperature on nutritional properties, total phenolic content and antioxidant capacity of quinoa seeds (Chenopodium quinoa Willd.). Ind. Crop. Prod. 2010, 32, 258-263. [CrossRef]

13. Pellegrini, M.; Gonzalesb, R.L.; Riccia, A.; Fontechac, J.; Lopez, J.F.; Alvarez, J.A.P.; Martos, M.V. Chemical, fatty acid, polyphenolic profile, techno-functional and antioxidant properties of flours obtained from quinoa (Chenopodium quinoa Willd) seeds. Ind. Crop. Prod. 2018, 111, 38-46. [CrossRef]

14. Khan, I.; Yousif, A.; Johnson, S.K.; Gamlath, S. Effect of sorghum flour addition on resistant starch content, phenolic profile and antioxidant capacity of durum wheat pasta. Food Res. Int. 2013, 54, 578-586. [CrossRef]

15. Chandrasekara, A.; Shahidi, F. Content of insoluble bound phenolics in millets and their contribution to antioxidant capacity. J. Agric. Food Chem. 2010, 58, 6706-6714. [CrossRef]

16. Ragaee, S.; Abdel-Aal, E.-S.M.; Noaman, M. Antioxidant activity and nutrient composition of selected cereals for food use. Food Chem. 2006, 98, 32-38. [CrossRef]

17. Yousif, A.; Nhepera, D.; Johnson, S. Influence of sorghum flour addition on flat bread in vitro starch digestibility, antioxidant capacity and consumer acceptability. Food Chem. 2012, 134, 880-887. [CrossRef] 
18. Nascimento, A.C.; Mota, C.; Coelho, I.; Gueifao, S.; Santos, M.; Matos, A.S.; Gimenez, A.; Lobo, M.; Samman, N.; Castanheira, I. Characterisation of nutrient profile of quinoa (Chenopodium quinoa), amaranth (Amaranthus caudatus), and purple corn (Zea mays L.) consumed in the North of Argentina: Proximates, minerals and trace elements. Food Chem. 2014, 148, 420-426. [CrossRef]

19. ASRO. Romanian Standards Catalog for Cereal and Milling Products Analysis; SR ISO 712:2005, SR 91:2007 and SR ISO 2171/2002; ASRO: Bucharest, Romania, 2008.

20. AACC International. Approved Methods of Analysis, Methods 46-11.02, 76-31.01 and 32-40.01, 11th ed.; American Association of Cereal Chemists International: St. Paul, MN, USA, 2000.

21. Asp, N.G.; Johansson, C.G.; Hallmer, H.; Siljestrom, M. Rapid enzymatic assay of insoluble and soluble dietary fiber. J. Agric. Food Chem. 1983, 31, 476-482. [CrossRef] [PubMed]

22. Gibson, T.S.; Solah, V.A.; McCleary, B.V. A procedure to measure amylose in cereal starches and flours with concanavalin A. J. Cereal Sci. 1997, 25, 111-119. [CrossRef]

23. Godon, B.; Wilhm, C. Primary Cereal Processing a Comprehensive Sourcebook; VCH: New York, NY, USA, 1994.

24. Banu, I.; Stoenescu, G.; Ionescu, V.; Aprodu, I. Physicochemical and rheological analysis of flour mill streams. Cereal Chem. J. 2010, 87, 112-117.

25. Aprodu, I.; Banu, I. Antioxidant properties of wheat mill streams. J. Cereal Sci. 2012, 56, 189-195. [CrossRef]

26. Miao, M.; Jiang, B.; Zhang, T.; Jin, Z.; Mu, W. Impact of mild acid hydrolysis on structure and digestion properties of waxy maize starch. Food Chem. 2011, 126, 506-513. [CrossRef]

27. Fairbanks, D.J.; Burgener, K.W.; Robison, L.R.; Andersen, W.R.; Ballon, E. Electrophoretic characterization of quinoa seed proteins. Plant Breed. 1990, 104, 190-195. [CrossRef]

28. Mokrane, H.; Amoura, H.; Belhaneche-Bensemra, N.; Courtin, C.M.; Delcour, J.A.; Nadjemi, B. Assessment of Algerian sorghum protein quality [Sorghum bicolor (L.) Moench] using amino acid analysis and in vitro pepsin digestibility. Food Chem. 2010, 121, 719-723. [CrossRef]

29. Hamaker, B.R.; Bugusu, B.A. In Proceedings of the Overview: Sorghum Proteins and Food Quality, Pretoria, South Africa, 2-4 April 2003.

30. United States Department of Agriculture Agricultural Research Service National Nutrient Database for Standard Reference Legacy Release, Basic Report. Available online: https://ndb.nal.usda.gov/ndb/foods/ show $/ 20035$ ?fgcd=\&manu=\&format=\&count=\&max=25\&offset=\&sort=default\&order=asc\&qlookup= QUINOA+CEREAL\%2C+UPC \%3A+729955573994\&ds=\&qt=\&qp=\&qa=\&qn=\&q=\&ing $=($ accessed on 13 April 2020).

31. Devi, P.B.; Vijayabharathi, R.; Sathyabama, S.; Malleshi, N.G.; Priyadarisini, V.B. Health benefits of finger millet (Eleusine coracana L.) polyphenols and dietary fiber: A review. J. Food Sci. Tech. 2014, 51, 1021-1040. [CrossRef]

32. Kalinova, J.; Moudry, J. Content and quality of protein in proso millet (Panicum miliaceum L.) varieties. Plant Food Hum. Nutr. 2006, 61, 45-49. [CrossRef]

33. Rooney, L.W. Sorghum and pearl millet lipids. Cereal Chem. 1978, 55, 584-590.

34. Jan, S.; Ghoroi, C.; Saxena, D.C. Effect of particle size, shape and surface roughness on bulk and shear properties of rice flour. J. Cereal Sci. 2017, 76, 215-221. [CrossRef]

35. Kurek, M.A.; Karp, S.; Wyrwisz, J.; Niu, Y. Physicochemical properties of dietary fibers extracted from gluten-free sources: Quinoa (Chenopodium quinoa), amaranth (Amaranthus caudatus) and millet (Panicum miliaceum). Food Hydrocoll. 2018, 85, 321-330. [CrossRef]

36. Lamothe, L.M.; Srichuwong, S.; Reuhs, B.L.; Hamaker, B.R. Quinoa (Chenopodium quinoa W.) and amaranth (Amaranthus caudatus L.) provide dietary fibres high in pectic substances and xyloglucans. Food Chem. 2015, 167, 490-496. [CrossRef]

37. Lai, V.; Lu, S.; Hsien He, W.; Chen, H.H. Non-starch polysaccharide compositions of rice grains with respect to rice variety and degree of milling. Food Chem. 2006, 101, 1205-1210. [CrossRef]

38. Chung, H.J.; Liu, Q.; Lee, L.; Wei, D. Relationship between the structure, physicochemical properties and in vitro digestibility of rice starches with different amylose contents. Food Hydrocoll. 2011, 25, 968-975. [CrossRef]

39. Kraithong, S.; Lee, S.; Rawdkuen, S. Physicochemical and functional properties of Thai organic rice flour. J. Cereal Sci. 2018, 79, 259-266. [CrossRef]

40. Marston, K.; Khouryieh, H.; Aramouni, F. Effect of heat treatment of sorghum flour on the functional properties of gluten-free bread and cake. LWT-Food Sci. Technol. 2016, 65, 637-644. [CrossRef] 
41. Rosell, C.M. Enzymatic manipulation of gluten-free breads. In Gluten-Free Food Science and Technology; Gallagher, E., Ed.; Wiley-Blackwell: Oxford, UK, 2009; pp. 83-98.

42. Schober, T.J. Manufacture of gluten-free specialty breads and confectionery products. In Gluten-Free Food Science and Technology; Gallagher, E., Ed.; Wiley-Blackwell: Oxford, UK, 2009; pp. 130-180.

43. Re, R.; Pellegrini, N.; Proteggente, A.; Pannala, A.; Yang, M.; Evans, C.R. Antioxidant activity applying an improved ABTS radical cation decolorization assay. Free. Radic. Bio. Med. 1999, 26, 1231-1237. [CrossRef]

44. Alvarez-Jubete, L.; Wijngaard, H.; Arendt, E.K.; Gallagher, E. Polyphenol composition and in vitro antioxidant activity of amaranth, quinoa buckwheat and wheat as affected by sprouting and baking. Food Chem. 2010, 119, 770-778. [CrossRef]

45. Jan, K.N.; Panesar, P.S.; Singh, S. Optimization of antioxidant activity, textural and sensory characteristics of gluten-free cookies made from whole Indian quinoa flour. LWT-Food Sci. Technol. 2015, 93, 573-582. [CrossRef]

46. Lindenmeier, M.; Hofmann, T. Influence of baking conditions and precursor supplementation on the amounts of the antioxidant pronyl-L-lysine in bakery products. J. Agric. Food Chem. 2004, 52, 350-354. [CrossRef] [PubMed]

47. Lopez-Contreras, J.J.; Zavala-Garcia, F.; Urias-Orona, V.; Martinez-Avila, G.C.; Rojas, R.; Nono-Medina, G. Chromatic, phenolic and antioxidant properties of sorghum bicolor genotypes. Not. Bot. Hort. Agrobot. Cluj-Napoca 2005, 43, 366-370. [CrossRef]

48. Chethan, S.; Malleshi, N.G. Finger millet polyphenols: Optimization of extraction and the effect of $\mathrm{pH}$ on their stability. Food Chem. 2007, 105, 862-870. [CrossRef]

49. Sreeramulu, D.; Reddy, C.V.K.; Manchala, R. Antioxidant activity of commonly consumed cereals, millets, pulses and legumes in India. Indian J. Biochem. Biophys. 2009, 46, 112-115.

50. Aloisi, I.; Parrotta, L.; Ruiz, K.B.; Landi, C.; Bini, L.; Cai, G.; Biondi, S.; Del Duca, S. New insight into quinoa seed quality under salinity: Changes in proteomic and amino acid profiles, phenolic content, and antioxidant activity of protein extracts. Front. Plant Sci. 2016, 7, 656. [CrossRef]

51. De la Hera, E.; Rosell, C.M.; Gomez, M. Effect of water content and flour particle size on gluten-free bread quality and digestibility. Food Chem. 2014, 151, 526-531. [CrossRef] [PubMed]

52. Taylor, J.R.N.; Emmambux, M.N. Developments in our understanding of sorghum polysaccharides and their health benefits. Cereal Chem. J. 2010, 87, 263-271. [CrossRef]

53. Wong, J.H.; Lau, T.; Cai, N.; Singh, J.; Pedersen, J.F.; Vensel, W.H.; Hurkman, W.J.; Wilson, J.D.; Lemaux, P.G.; Buchanan, B.B. Digestibility of protein and starch from sorghum (Sorghum bicolor) is linked to biochemical and structural features of grain endosperm. J. Cereal Sci. 2009, 49, 73-82. [CrossRef]

54. Li, G.; Zhu, F. Quinoa starch: Structure, properties, and applications. Carbohydr. Polym 2018, 181, 851-861. [CrossRef] [PubMed]

Publisher's Note: MDPI stays neutral with regard to jurisdictional claims in published maps and institutional affiliations.

(C) 2020 by the authors. Licensee MDPI, Basel, Switzerland. This article is an open access article distributed under the terms and conditions of the Creative Commons Attribution (CC BY) license (http://creativecommons.org/licenses/by/4.0/). 